\title{
Therapeutic Potential of Apium graveolens on the Reproductive System of Cadmium Treated Male Rats
}

\author{
Sushanth N. K. ${ }^{1}$, Vijayaraghavan R. ${ }^{2}$, S. Vijayalakshmi ${ }^{3}$, Senthilkumar Sivanesan ${ }^{4}$
}

\begin{abstract}
1Department of Research and Development, Saveetha Institute of Medical and Technical Sciences, Thandalam, Chennai, Tamilnadu, India. ${ }^{2}$ Department of Research and Development, Saveetha Institute of Medical and Technical

Sciences, Thandalam, Chennai, Tamilnadu, India. ${ }^{3}$ Department of Anatomy, Saveetha Institute of Medical and Technical Sciences, Thandalam, Chennai, ${ }^{4}$ Department of Research and Development, Saveetha Institute of Medical and Technical Sciences, Thandalam, Chennai, Tamilnadu, India.
\end{abstract}

\section{ABSTRACT}

\section{BACKGROUND}

Cadmium (Cd) is a well - known environmental toxin that is naturally present in air, water and soil. The reproductive system is most vulnerable to oxidative damage and therefore most affected by Cd. Zinc (Zn) is an essential antioxidant and a chelating agent that is capable of protecting the testis from $\mathrm{Cd}$ induced toxicity. Apium graveolens commonly known as Celery is a herbal plant rich in antioxidants and it improves various sperm parameters.

\section{METHODS}

Male Wistar albino rats were randomly divided into 7 groups. Control received $0.5 \%$ Carboxy-Methyl Cellulose (CMC) in distilled water; the experimental groups namely $\mathrm{Cd}$ received $10 \mathrm{mg} / \mathrm{Kg}$ body weight of $\mathrm{CdCl}_{2} ; \mathrm{Cd}+\mathrm{Zn}$ received $10 \mathrm{mg} / \mathrm{Kg}$ bodyweight of $\mathrm{CdCl}_{2}+40 \mathrm{mg} / \mathrm{Kg}$ body weight of $\mathrm{ZnCl}_{2}$; $\mathrm{Cd}+\mathrm{AG} 200$ received $10 \mathrm{mg} / \mathrm{Kg}$ bodyweight of $\mathrm{CdCl}_{2}+200 \mathrm{mg} / \mathrm{Kg}$ body weight of Apium graveolens; Cd + AG400 received $10 \mathrm{mg} / \mathrm{Kg}$ body weight of $\mathrm{CdCl}_{2}+400 \mathrm{mg} / \mathrm{Kg}$ body weight of Apium graveolens; $\mathrm{Cd}+\mathrm{AG} 200+\mathrm{Zn}$ received $10 \mathrm{mg} / \mathrm{Kg}$ bodyweight of $\mathrm{CdCl}_{2}+200 \mathrm{mg} / \mathrm{Kg}$ body weight of Apium graveolens $+40 \mathrm{mg} / \mathrm{Kg}$ body weight of $\mathrm{ZnCl}_{2}$; $\mathrm{Cd}+\mathrm{AG} 400+$ $\mathrm{Zn}$ received $10 \mathrm{mg} / \mathrm{Kg}$ bodyweight of $\mathrm{CdCl}_{2}+400 \mathrm{mg} / \mathrm{Kg}$ body weight of Apium graveolens $+40 \mathrm{mg}$ / Kg body weight of $\mathrm{ZnCl}_{2}$ all in $0.5 \% \mathrm{CMC}$. Hydroalcoholic extract of Apium graveolens was used in this experiment. The experiment was conducted for a duration of 56 days. Histopathology, sperm analysis, lipid peroxidation and hormone assays were performed. The therapeutic potential of Apium graveolens at two doses (200 and $400 \mathrm{mg} / \mathrm{Kg}$ body weight) with and without $\mathrm{Zn}$ supplementation was evaluated in this experiment.

\section{RESULTS}

Rats treated with Cd showed severe testicular damages. Zn offered protection from the damages done by cadmium. The hydroalcoholic extract of Apium graveolens at doses of $200 \mathrm{mg} / \mathrm{Kg}$ body weight showed better protective effect than $400 \mathrm{mg} / \mathrm{Kg}$ body weight and the protecting nature was enhanced by zinc supplementation.

\section{CONCLUSIONS}

Hydroalcoholic extract of Apium graveolens at a dose of $200 \mathrm{mg} / \mathrm{Kg}$ body weight supplemented with $\mathrm{Zn}$ offers the best protection to the testes against damages caused by Cd.

\section{KEY WORDS}

Infertility, Testis, Cadmium, Zinc, Apium graveolens, Testosterone, Spermatogenesis, Germ Cells, Oxidative Stress, Blood-Testis Barrier
Corresponding Author:

Dr Sushanth N K.

Ph.D, Scholar,

Department of Research and Development, Saveetha Institute of Medical and Technical Sciences, Thandalam, Chennai,

Tamilnadu, India.

E-mail: birdmanturnedanatomistatpeace @outlook.com

DOI: $10.14260 /$ jemds/2020/575

How to Cite This Article:

Sushanth NK, Vijayaraghavan $R$, Vijayalakshmi S, et al Therapeutic potential of Apium graveolens on the reproductive system of cadmium treated male rats. $J$ Evolution Med Dent Sci 2020;9(36):26452651, DOI: 10.14260/jemds/2020/575

Submission 01-06-2020,

Peer Review 28-07-2020,

Acceptance 04-08-2020,

Published 07-09-2020.

Copyright (C) 2020 JEMDS. This is an open access article distributed under Creative Commons Attribution License [Attribution 4.0 International (CC BY 4.0)] 


\section{BACKGROUND}

Infertility is a major health concern in human society. Environmental and occupational exposure to toxic substances such as cadmium (Cd) is one of the most important aetiologies. $\mathrm{Cd}$, a toxic transitional metal element, can cause irreversible damage to various tissues of the body including testis. ${ }^{1} \mathrm{Cd}$ is found in nature as cadmium oxide, cadmium sulphide, cadmium carbonate and cadmium chloride and it accumulates in soil from various human activities such as mining and smelting. Cd is used in the manufacturing of $\mathrm{Ni}$ - Cd battery, plastics, fertilizers and several other industries.

Once it enters the body, it initiates free radical production that causes oxidative damage and triggers pathological conditions in humans as well as animals. ${ }^{2,3}$ Various organ systems of our body such as the digestive, respiratory, nervous, excretory and most commonly the reproductive, which tops the list of the 'most affected organ systems by cadmium in the body' are affected ultimately resulting in infertility.

Though the basic mechanism underlying how cd induces pathology is not known completely, it is clear that $\mathrm{Cd}$ can induce oxidative response in various organs such as reproductive organs especially testis by breaching Blood Testis -Barrier (B-T-B). ${ }^{1}$ Cd induces oxidative stress by either displacement of redox - active metals, depletion of redox scavengers, inhibition of anti - oxidant enzymes or inhibition of the electron transport chain resulting in mitochondrial damage. ${ }^{4,5}$

All organs, tissues, and fluids of the body contain an essential antioxidant trace element, the zinc. It is the second most abundant trace element in the body. ${ }^{6}$ It plays an important role in cell proliferation, differentiation, normal growth, immune functions, and wound healing. ${ }^{1} \mathrm{Zn}$ is required by more than 300 enzymes for their activity. ${ }^{7}$

Antioxidants like vitamin C, vitamin E, carotenes, phenolic acids, phytate and phytoestrogens which are found in many of the world's medicinal plant species have great free radical scavenging potential and reduce disease risk. ${ }^{8}$ Apium graveolens commonly known as Celery belongs to the parsley (Umbelliferae) species of the Apiaceae family. It is scented, with solid and fleshy stems growing up to a height of about a meter on an average. ${ }^{9}$ This plant is rich in active compounds such as phytoestrogens, which can be highly effective in the treatment of infertility and reproductive system related problems Celery without any destructive effect increases spermatogenesis in male rats. Antioxidant compounds increase sperm function and can improve fertility. ${ }^{10}$

In the present study, the protective effect of hydroalcoholic extract of Apium graveolens with and without zinc supplementation on cadmium treated rats has been studied. Previous studies have shown that the rat testes exposed to cadmium are highly affected resulting in germ cell damage, impaired spermatogenesis and steroidogenesis by inducing ROS and thereby depleting antioxidants. Zinc being a chelator and antioxidant, in this experiment, it is expected to overcome cadmium toxicity. Apium graveolens is expected to prevent germ cell damage by supplementing antioxidants naturally present in them.

\section{METHODS}

Male Wistar albino rats were used for this study and were obtained from Biogen (Bengaluru, India) and kept in the animal house of Saveetha Medical College, Chennai, India. The rats weighed 180 - $200 \mathrm{~g}$ and were kept in a controlled condition for 5 days for acclimatization and kept in the same condition until the end of the experiment. The animals were housed in a plastic cage with food and water supply, floored by husk which was replaced every 5 days. After adaptation to the new environment, the rats were randomly divided into 7 groups of 6 animals each as follows-

Group 1 - Control- received $1 \mathrm{ml}$ of $0.5 \%$ CMC suspension in distilled water.

Group 2 - Cd - received $10 \mathrm{mg} / \mathrm{Kg}$ bw of $\mathrm{CdCl}_{2}$ in $0.5 \% \mathrm{CMC}$.

Group 3 - Cd + Zn- received $10 \mathrm{mg} / \mathrm{Kg}$ bw of $\mathrm{CdCl}_{2}+40 \mathrm{mg} / \mathrm{Kg}$ bw of $\mathrm{ZnCl}_{2}$ in $0.5 \% \mathrm{CMC}$

Group 4 - Cd + AG200- received $10 \mathrm{mg} / \mathrm{Kg}$ bw of $\mathrm{CdCl}_{2}+200$ $\mathrm{mg} / \mathrm{Kg}$ bw of Apium graveolens in $0.5 \% \mathrm{CMC}$.

Group 5 - Cd + AG400- received $10 \mathrm{mg} / \mathrm{Kg}$ bw of $\mathrm{CdCl}_{2}+400$ $\mathrm{mg} / \mathrm{Kg}$ bw of Apium graveolens in $0.5 \% \mathrm{CMC}$.

Group 6 - Cd + AG200 + Zn- received 10 mg / Kg bw of $\mathrm{CdCl}_{2}+$ $200 \mathrm{mg} / \mathrm{Kg}$ bw of Apium graveolens $+40 \mathrm{mg} / \mathrm{Kg}$ bw of $\mathrm{ZnCl}_{2}$ in $0.5 \% \mathrm{CMC}$.

Group 7 - Cd + AG400 + Zn- received $10 \mathrm{mg} / \mathrm{Kg}$ bw of $\mathrm{CdCl}_{2}+$ $400 \mathrm{mg} / \mathrm{Kg}$ bw of Apium graveolens $+40 \mathrm{mg} / \mathrm{Kg} \mathrm{bw}$ of $\mathrm{ZnCl}_{2}$ in $0.5 \%$ CMC.

\section{Abbreviations \\ CMC- Carboxy Methyl Cellulose, Cd-Cadmium chloride, Zn- Zinc chloride, AG-Apium graveolens.}

\section{Statistical Analysis}

Sigma Plot 13.0 Systat software, USA was used for statistical analysis.

\section{RESULTS}

\section{Morphological Observation of Testis}

The cadmium treated rat testes were shrunken and pale and weighed less compared to control. The rat testes treated with $\mathrm{Cd}+\mathrm{AG} 200+\mathrm{Zn}$ showed rich vascularity and near normal morphology and weight.

\section{Concentration of Sperm}

The concentration of sperm in Cd group $\left(24.2 \pm 3.1 \times 10^{6} / \mathrm{mL}\right)$ was significantly $(<0.001)$ lower by 3 folds than control. In $\mathrm{Cd}$ + Zn group, the concentration $\left(47.8 \pm 3.4 \times 10^{6} / \mathrm{mL}\right)$ was 
significantly $(<0.001)$ lower by 1.5 folds than control but significantly $(<0.001)$ higher by 2 folds than the Cd group. In $\mathrm{Cd}+\mathrm{AG} 200$ group sperm concentration $(61.4 \pm 1.5 \mathrm{X} \mathrm{10} / \mathrm{mL})$ was significantly $(<0.001)$ higher by 2.5 folds than Cd group, however no significant difference from control group was observed. In Cd + AG 400 group the sperm concentration (38.7 $\left.\pm 2.6 \times 10^{6} / \mathrm{mL}\right)$ was significantly $(<0.001)$ lower by 1.9 folds than control but significantly $(<0.001)$ higher by 1.6 folds than Cd group. In Cd + AG $200+\mathrm{Zn}\left(71.1 \pm 1.8 \times 10^{6} / \mathrm{mL}\right)$ and $\mathrm{Cd}+$ $\mathrm{AG} 400+\mathrm{Zn}\left(50.5 \pm 11.6 \times 10^{6} / \mathrm{mL}\right)$ groups the sperm concentration was significantly $(<0.001)$ higher by 2.9 and 2.1 folds respectively than $\mathrm{Cd}$ group, however no significant difference from control was observed.

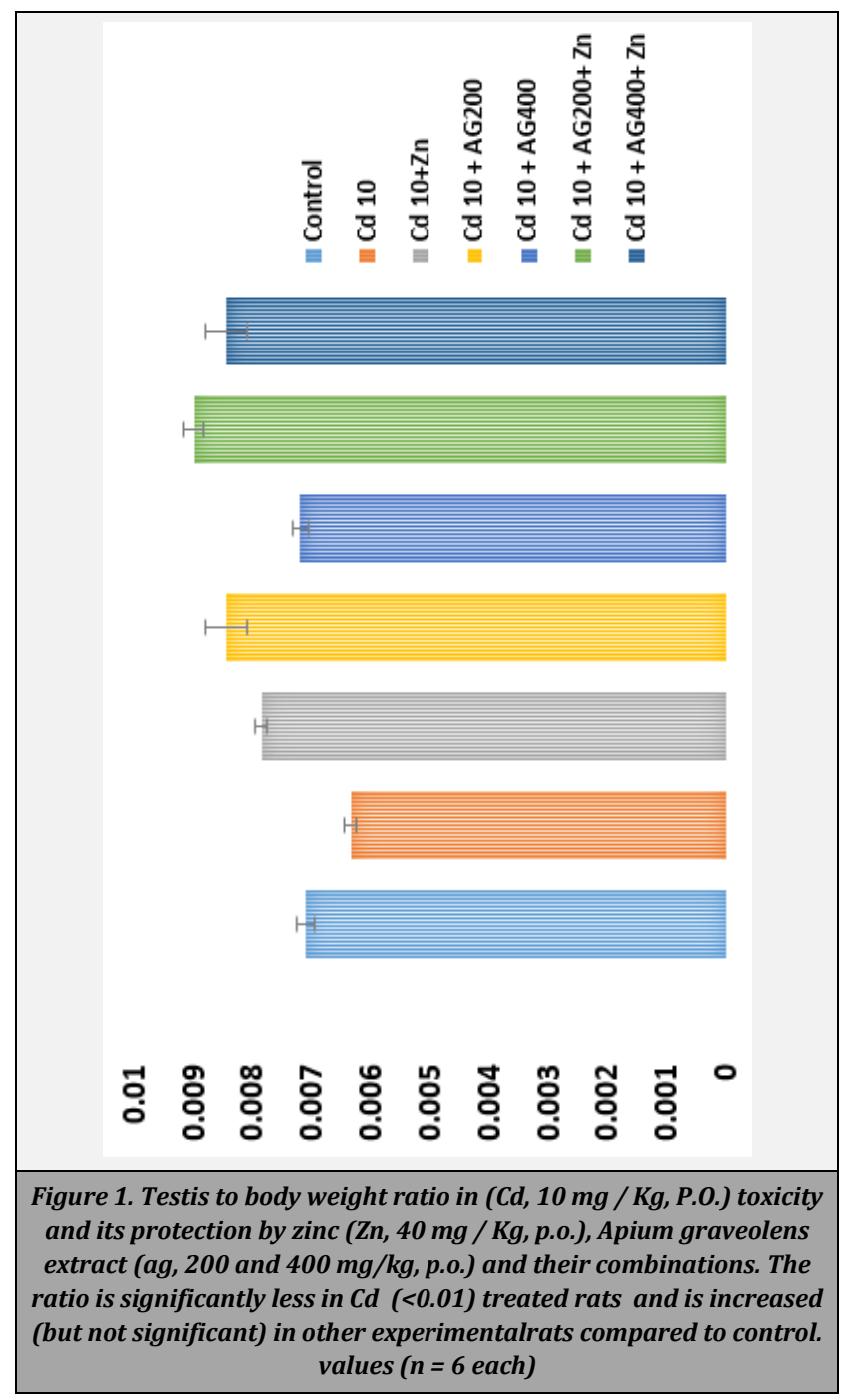

\section{Motility of Sperm}

The motility of sperm in Cd group $(3.4 \pm 0.5 \%)$ was significantly $(<0.001)$ lower by 17.4 folds than control. In $\mathrm{Cd}+$ Zn group, the motility $(39.3 \pm 2.2 \%)$ was significantly (< 0.001 ) lower by 1.5 folds than control and at the same time significantly $(<0.001)$ higher by 11.2 folds than the Cd group. In Cd + AG 200 (43.3 $\pm 2.6 \%)$ and Cd + AG 400 (15.8 $\pm 1.5 \%)$ groups, the sperm motility was significantly $(<0.001)$ lower by $1.4,1.3$ and 3.7 folds respectively than control but significantly $(<0.001)$ higher by $12.3,12.7$ and 4.6 folds respectively than Cd group. In Cd + AG $200+$ Zn group the sperm motility (48.4 $\pm 2.3 \%$ ) was significantly ( $<0.001$ ) higher by 14.2 folds than Cd group however, no significant difference from control was observed. In Cd + AG $400+$ Zn groups the sperm motility $(37.5$ $\pm 4 \%$ ) was significantly $(<0.001)$ lower by 1.6 folds than control but significantly $(<0.001)$ higher by 11 folds than $\mathrm{Cd}$ group.

\section{Viability of Sperm}

The viability of sperm in $\mathrm{Cd}$ group $(13.9 \pm 1.8 \%)$ was significantly $(<0.001)$ lower by 5.2 folds than control. In $\mathrm{Cd}+$ Zn group, the viability $(51.5 \pm 2 \%)$ was significantly $(<0.001)$ lower by 1.5 folds than control and at the same time significantly $(<0.001)$ higher by 3.7 folds than the Cd group. In $\mathrm{Cd}+\mathrm{AG} 200$ group, the viability (53.7 $\pm 3.4 \%)$ was significantly $(<0.001)$ higher by 3.9 folds but no significant difference from control was observed. In Cd + AG 400 group, the sperm viability $(20.4 \pm 1.2 \%)$ was significantly $(<0.001)$ lower by 3.5 folds than control but significantly $(<0.001)$ higher by 1.5 folds than Cd group. In Cd + AG $200+$ Zn group the viability $(69.3 \pm 1.4 \%)$ was significantly $(<0.001)$ higher by 5 folds but no significant difference from control was observed. In Cd + AG $400+\mathrm{Zn}(48.1 \pm 3.7 \%)$ group the sperm viability was significantly $(<0.001)$ lower by 1.5 folds than control but significantly $(<0.001)$ higher by 3.5 folds than $\mathrm{Cd}$ group.

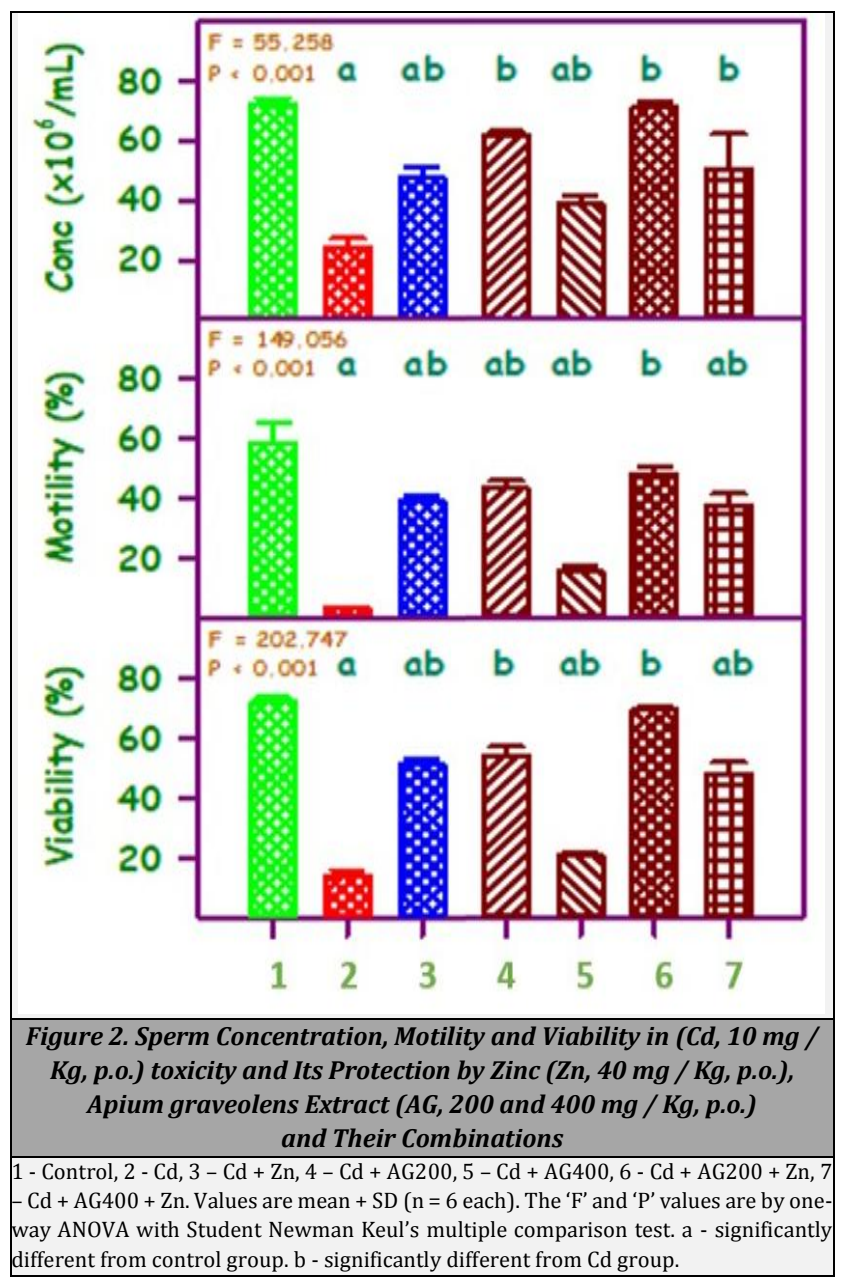

\section{Lipid Peroxidation}

The lipid peroxidation measured in terms of malondialdehyde (MDA) for various groups is as follows. The level of MDA in Cd 
group $(4.06 \mathrm{nmol} / \mathrm{mL})$ was significantly $(<0.001)$ higher by 2.5 folds than the control. In $\mathrm{Cd}+\mathrm{Zn}$ group the level of MDA $(3.03 \mathrm{nmol} / \mathrm{mL})$ was significantly $(<0.001)$ higher by 1.9 folds than control but significantly $(<0.001)$ lower by 1.3 folds than the Cd group. In Cd + AG 200 group the level of MDA $(2.5$ $\mathrm{nmol} / \mathrm{mL}$ ) was significantly $(<0.001)$ lower by 1.6 folds than the Cd group. At the same time, no significant difference from control was observed in this group. In Cd + AG 400 group the level of MDA $(3.21 \mathrm{nmol} / \mathrm{mL})$ was significantly $(<0.001)$ higher by 1.9 folds than control but significantly $(<0.001)$ lower by 1.3 folds than Cd group. In Cd + AG $200+$ Zn group, the level of MDA $(1.92 \mathrm{nmol} / \mathrm{mL})$ was significantly $(<0.001)$ lower by 2.1 folds than Cd group, however no significant difference from control group was observed. Finally in Cd + AG $400+\mathrm{Zn}$ group, the level of MDA $(3.28 \mathrm{nmol} / \mathrm{mL})$ was significantly $(<0.001)$ higher by 2 folds than control group, but no significant diffrence from Cd group was found.

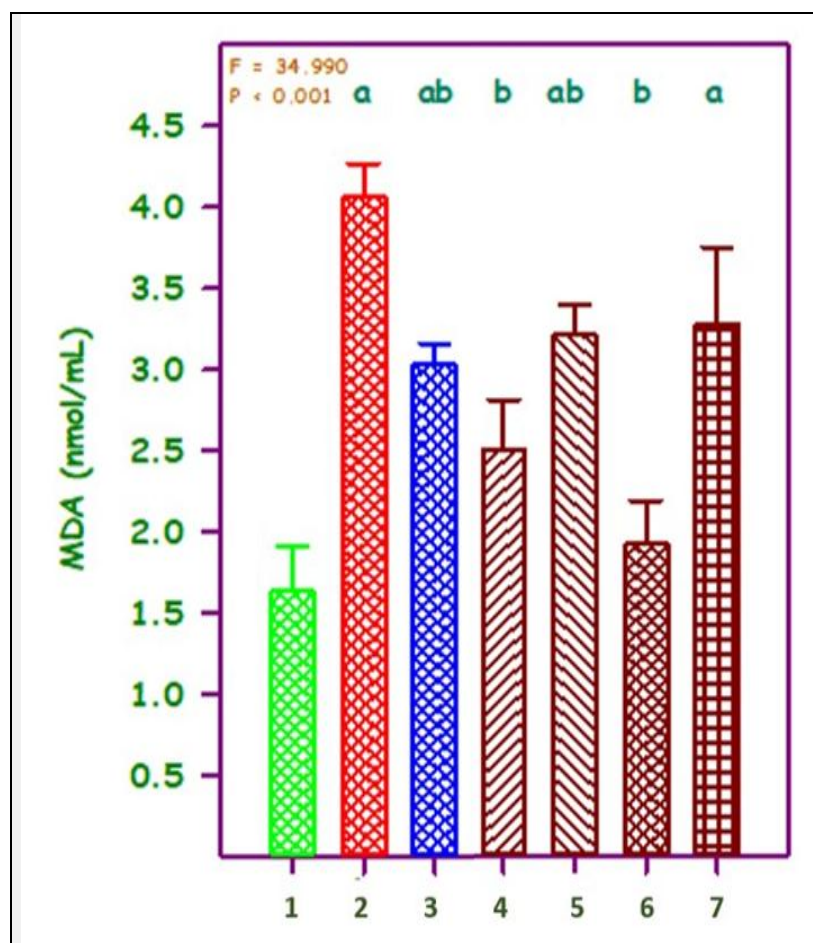

Figure 3. MDA Level in LPO Expressed in nmoles of MDA Formed / $\mathrm{mL}$ Cadmium (Cd, $10 \mathrm{mg} / \mathrm{Kg}$, p.o.). Toxicity and Protection from It by Zinc (Zn, $40 \mathrm{mg} / \mathrm{Kg}$, p.o.), Apium graveolens Extract (AG, 200 and $400 \mathrm{mg}$ / Kg, p.o.) and Their Combinations

1 - Control, 2 - Cd, 3 - Cd + Zn, 4 - Cd + AG200, 5 - Cd + AG400, 6 - Cd + AG200 + Zn, 7 $-\mathrm{Cd}+\mathrm{AG} 400+\mathrm{Zn}$. Values are mean $+\mathrm{SD}(\mathrm{n}=6$ each). The ' $\mathrm{F}$ ' and ' $\mathrm{P}$ ' values are by one way ANOVA with Student Newman Keul's multiple comparison test. a - significantly different from control group. B - significantly different from Cd group.

\section{Histopathology}

Routine Haematoxylin and Eosin staining was done to observe the changes in the micro anatomical features of testis in various experimental groups and compared with control group. There were severe pathological changes in the testis of cadmium chloride treated rats on microscopic examination. The seminiferous epithelium appeared thin due to degeneration of spermatogenic cells, distortion of seminiferous tubules lined by Sertoli cells with increased collagen deposition, incomplete and arrested spermatogenesis, incomplete or loss of spermatogenesis, empty tubules without spermatozoa, thickening of basal membrane with fibrosis, vacuolization of the Sertoli cells and multinucleation of the spermatogenic cells transforming into/becoming multi - nucleated giant cells with fragmented nucleus and shrunken cellular morphology indicating apoptotic pathology. In $\mathrm{Cd}+\mathrm{Zn}$ treated rats, these pathological changes were reduced, and seminiferous tubules appeared near normal hence less damage compared to $\mathrm{Cd}$ group was observed. The $\mathrm{Cd}+\mathrm{AG} 200$ group showed very significant protection unlike $\mathrm{Cd}+\mathrm{AG} 400$ group which showed damage to the seminiferous epithelium, with slightly increased interstitial space but exhibited better integrity of cellular details compared to cadmium treated groups. Cd + AG200 + Zn treated rats showed the best histological details equivalent to control as evident by the observation under microscope. The seminiferous tubules and its epithelium were intact with various stages of developing germ cells in the epithelium and numerous spermatozoans in the lumen. However, Cd + AG400 + Zn showed slightly distorted seminiferous tubule lumen and epithelium with few spermatozoans in the lumen. Hence the rats in the treatment group which received Cd + AG200 + Zn showed that the extract was able to preserve the cellular architecture from cadmium induced alterations to a significant extent.

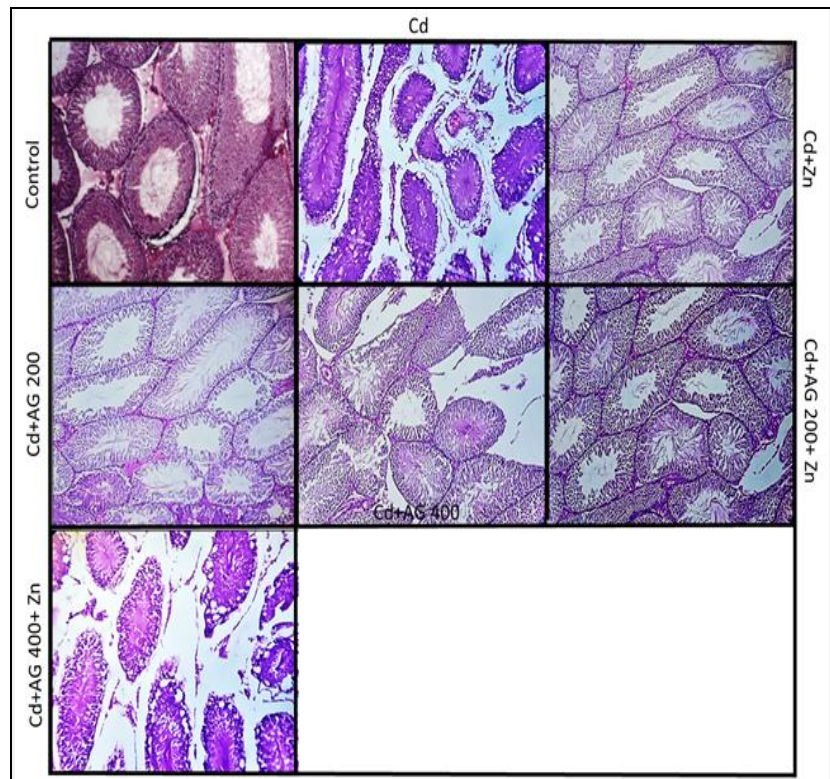

Figure 4. Photomicrograph of $\mathrm{H} \& \mathrm{E}$ stained section of testis of control and various experimental rats at 20x magnification. Free sperms can be seen in the lumen of seminiferous tubules of control rats. Thick seminiferous epithelium is also seen with various stages of spermatogenesis. The interstitial space, thickness of seminiferous epithelium and population of mature sperm in the lumen of seminiferous tubules are compared

\section{Viability of Sperm}

The viability of sperm in Cd group $(13.9 \pm 1.8 \%)$ was significantly $(<0.001)$ lower by 5.2 folds than control. In $\mathrm{Cd}+$ Zn group, the viability $(51.5 \pm 2 \%)$ was significantly $(<0.001)$ lower by 1.5 folds than control and at the same time significantly $(<0.001)$ higher by 3.7 folds than the Cd group. In Cd + AG 200 group,oup, the viability $(53.7 \pm 3.4 \%)$ was significantly $(<0.001)$ higher by 3.9 folds but no significant difference from control was observed. In Cd + AG 400 group, the sperm viability $(20.4 \pm 1.2 \%)$ was significantly $(<0.001)$ lower by 3.5 folds than control but significantly $(<0.001)$ 
higher by 1.5 folds than Cd group. In Cd + AG $200+$ Zn group the viability $(69.3 \pm 1.4 \%)$ was significantly $(<0.001)$ higher by 5 folds but no significant difference from control was observed. In Cd + AG $400+\mathrm{Zn}(48.1 \pm 3.7 \%)$ group the sperm viability was significantly $(<0.001)$ lower by 1.5 folds than control but significantly $(<0.001)$ higher by 3.5 folds than $\mathrm{Cd}$ group.

\section{Hormone Analysis}

Testosterone Hormone (TST) - In Cd group, the level of TST $(1.9 \mathrm{ng} / \mathrm{mL})$ was significantly $(<0.001)$ lower by 2.6 folds than control. In Cd $+\mathrm{Zn}$ treatment group, the level $(3.4 \mathrm{ng} / \mathrm{mL})$ was significantly $(<0.001)$ higher by 1.8 folds than Cd group, however no significant difference from control group was observed. In Cd + AG200 group, TST level (3.9 ng/mL) was significantly $(<0.001)$ higher by 2 folds but no significant difference from control group was noted. In Cd + AG400 group, level of TST $(3.1 \mathrm{ng} / \mathrm{mL})$ was significantly $(<0.001)$ lower by 1.3 folds than control, but at the same time was significantly $(<$ 0.001 ) higher by 1.6 folds than Cd group. In Cd + AG200 + Zn and Cd + AG400 + Zn the level of TST was $4.2 \mathrm{ng} / \mathrm{mL}$ and 3.9 $\mathrm{ng} / \mathrm{mL}$ respectively. In both these groups the level of TST was significantly $(<0.001)$ higher than Cd group by 2.2 and 2 folds respectively and no significant difference from control group was found.

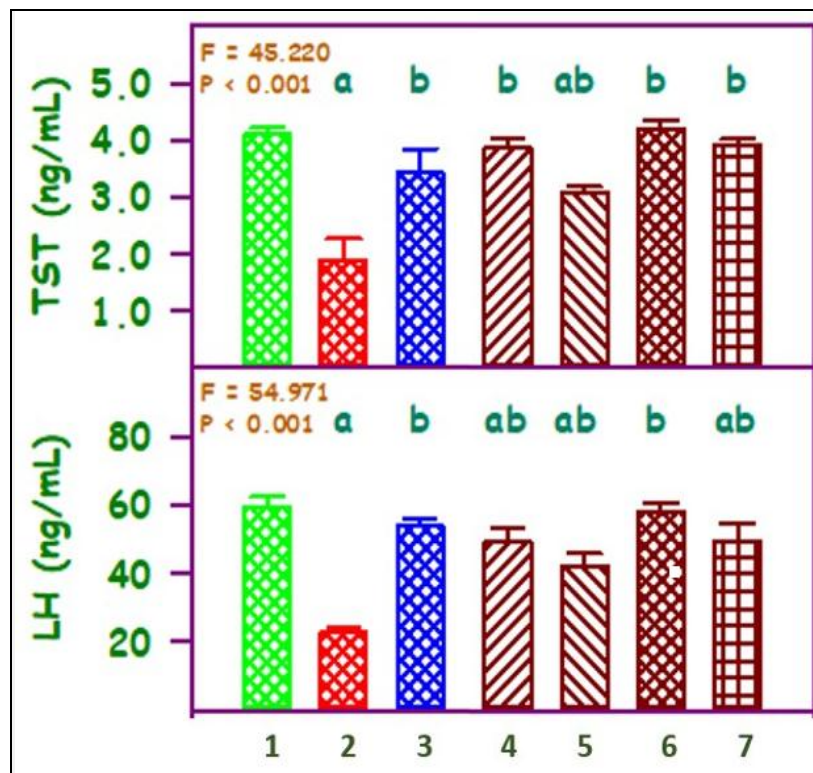

Figure 5. Serum hormone levels in cadmium (Cd, $10 \mathrm{mg} / \mathrm{Kg}, \mathrm{p.o}$.) toxicity and its protection by zinc ( $\mathrm{Zn}, 40 \mathrm{mg} / \mathrm{Kg}$, p.o.), Apium graveolens extract ( $A G, 200$ and $400 \mathrm{mg} / \mathrm{Kg}$, p.o.) and their combinations. 1-Control, 2-Cd, 3-Cd + Zn, 4-Cd + AG200, 5-Cd + AG400, 6-Cd + $\mathrm{AG200}+\mathrm{Zn}, \mathbf{7}-\mathrm{Cd}+\mathrm{AG400}+\mathrm{Zn}$

Values are mean $+\mathrm{SD}(\mathrm{n}=4$ each). The ' $\mathrm{F}$ ' and ' $\mathrm{P}$ ' values are by one - way ANOVA with Student Newman Keul's multiple comparison test. a - significantly different from control group. $\mathrm{b}$ - significantly different from Cd group.

Luteinizing Hormone (LH) - In Cd group, the level of LH (22.6 ng / mL) was significantly $(<0.001)$ lower by 2.6 folds than control. In Cd + Zn treatment group, the level (53.8 ng / $\mathrm{mL}$ ) was significantly $(<0.001)$ higher by 2.4 folds than $\mathrm{Cd}$ group, however no significant difference from control group was observed. In Cd + AG200 group, LH level (49.4 ng / mL) was significantly $(<0.001)$ lower by 1.2 folds than control group but higher by 2.2 folds than Cd group. In Cd + AG400 group, level of LH (42.1 ng / $\mathrm{mL})$ was significantly $(<0.001)$ lower by 1.4 folds than control, but at the same time it was significantly $(<0.001)$ higher by 1.9 folds than Cd group. In $\mathrm{Cd}$ $+\mathrm{AG} 200+\mathrm{Zn}$ group the level of LH (58.0 ng / mL) was significantly $(<0.001)$ higher than Cd group by 2.6 folds, but no significant difference from control group was found. In $\mathrm{Cd}$ + AG400 + Zn the level of LH (49.6 ng / mL) was significantly (< 0.001) lower than control group by 1.2 folds but significantly $(<0.001)$ higher than Cd group by 2.2 folds.

\section{DISCUSSION}

Cd causes a number of metabolic and micro anatomical changes and cell death in living organisms ${ }^{3,11,12}$. Impairment of reproductive capacity by causing severe degeneration of testis, damage to seminiferous tubules and necrosis are some of the consequences of cadmium toxicity in rats. ${ }^{13}$ Cadmium causes alteration in androgen status which is indicated by its effect on the weight of the sex organs. ${ }^{14}$ In the present study it was found that the testis to body weight ratio decreased and appeared shrunken in Cd treated rats whereas in all the other treatment groups this ratio did not vary significantly. This could be due to loss of germ cells and interstitial cells resulting in infertility. Like kidney and liver, in testis also $\mathrm{Cd}$ administration results in oxidative damage following generation of ROS15. Cadmium induced LPO is at a higher level because the Leydig cell mitochondria and microsomes contain high amount of membrane lipid content. ${ }^{16}$

In this study increased LPO was noted in rats treated with $\mathrm{Cd}$ and it significantly reduced in treatment groups. In spite of the existence of the blood-testis barrier in testis, oxidative stress can severely damage spermatogenic cells including the basement membrane of the seminiferous tubules due to the high metabolism and cell proliferation in testicular tissue.17,18 Histopathology of testis revealed degeneration of seminiferous epithelium and depletion of germ cells due to this reason. The ROS generated by Cd alter the mechanism of steroidogenesis and hormone production by disturbing membrane integrity of cells. ${ }^{19}$ In the present study the decreased level of $\mathrm{LH}$ and Testosterone hormones in $\mathrm{Cd}$ treated rats compared to $\mathrm{Zn}$ and $\mathrm{AG}$ treated ones can be attributed to the fall in total percentage of healthy testosterone producing Leydig cells caused due to ROS. ${ }^{20}$

Fertility is greatly influenced by oxidative stress. ${ }^{21}$ Infertile people have a low antioxidant level and high ROS level in their semen. ${ }^{22}$ Free radicals induce oxidative stress which is defended by antioxidants in normal conditions. Generally, antioxidants are free radical scavengers which are capable of suppressing or opposing the formation and or their actions of ROS.23,24 These include enzymatic and non-enzymatic antioxidants such as vitamin C, zinc, vitamin E etc. ${ }^{22}$ In the present study Apium graveolens was used as source of antioxidants Vitamin $\mathrm{C}$ and $\mathrm{E}$ and zinc as antioxidant cum chelating agent.

Zn could prevent the acute toxicity of cadmium in the testis of rats and mice. ${ }^{1}$ In the present study animals treated with $\mathrm{Cd}$ $+\mathrm{Zn}, \mathrm{Cd}+\mathrm{AG} 200+\mathrm{Zn}$ and Cd + AG400 + Zn, clearly showed protective effect of $\mathrm{Zn}$ over $\mathrm{Cd}$. Even though zinc and cadmium share many similarities in their physical and chemical 
properties, zinc counteracts a number of toxic effects of cadmium including protection against LPO. Similar result was found in this study also. Zinc plays a major role in protecting the physiological processes such as cellular response to oxidative stress, DNA repair, cell cycle and apoptosis of a cell. 25 It is an important antioxidant and an integral component of the superoxide dismutase enzyme, which can convert superoxide anion into $\mathrm{H}_{2} \mathrm{O}_{2}$ and oxygen molecules. ${ }^{26}$ In a study, cadmium was administered subcutaneously and its adverse effects were studied. It was found that when cadmium was given in combination with zinc simultaneously, the protective effect of zinc was exhibited clearly, and the toxicity caused was less when cadmium was administered alone. ${ }^{1,27}$ The present study found similar results. This could be due to antioxidant and chelating properties of zinc. Zinc plays an important role in the physiology of spermatozoa also. It is believed to have a role in production of sperm and viability. ${ }^{7}$ The rats treated with $\mathrm{Cd}+$ $\mathrm{Zn}$ and $\mathrm{Cd}+\mathrm{AG} 200+\mathrm{Zn}$ showed increased sperm parameters such as concentration, viability and motility in addition to increased TST and LH levels compared to Cd alone treated rats which supports the argument of protective effect of $\mathrm{Zn}$ against $\mathrm{Cd}$ as was demonstrated in the present study. The same was reflected in the microanatomical details also. The histological features of testis in $\mathrm{Zn}$ treated rats was very well preserved.

Normal testicular function is restored to some extent by treating the animals with Vit $\mathrm{C}$ and Vit $\mathrm{E}$ before exposing to $\mathrm{Cd}$ because these enzymes can reduce production of ROS in testis ${ }^{28}$. In the present study, Apium graveolens is rich in Vit $\mathrm{C}$ and $\mathrm{E}$ hence near normal structural and functional integrity was maintained in those groups treated with it. The rats treated with hydroalcoholic extract of Apium graveolens showed a significantly good protective effect in the present study. The weight of animals did not show any significant variation as that of $\mathrm{Cd}$ treated in which it decreased. Due to its antioxidant and anti-inflammatory properties, celery is able to protect the tissue against harmful effects of free radicals on cells preventing cell death and loss of weight or tissue volume. Previous investigations prove similar results. ${ }^{29}$

In the present study Apium graveolens treated rats showed significantly less amount of lipid peroxidation due to its antioxidant properties. The histological features of the testes were very well preserved in Cd + AG200 and CD + AG200 + Zn treated rats due to the antioxidant properties of celery. In the evolution and proliferation of germ cells and spermatid differentiation, the level of testosterone is the effective and the most important androgenic hormone and it directly affects Sertoli cells stimulating secretion of testosterone. ${ }^{30}$ the hydroalcoholic extract of celery increases testosterone secretion. $^{31}$ Antioxidants affect hypothalamic-pituitarytesticular axis there by increase sperm count and fertility. ${ }^{32}$

The rats treated with celery showed relatively increased number of germ cells and thick seminiferous epithelium as evident by the histological examinations in the present study. An important parameter to evaluate the function of reproductive system is measuring the blood concentration of reproductive hormones. In the present study, testosterone levels were estimated, and it showed significant rise in $\mathrm{Cd}+$ AG200 + Zn treatment group. Testosterone affects seminiferous tubules and induces spermatogenesis. ${ }^{33}$ The dose of Apium graveolens $400 \mathrm{mg} / \mathrm{Kg}$ body weight was not very effective with or without $\mathrm{Zn}$ instead it caused some degree of tissue damage as evident by various biochemical, pathological, micro anatomical and morphological examinations of the testis tissue and this could be due to poor dose response or the actual reason needs to be explored.

\section{CONCLUSIONS}

The present study clearly demonstrated that cadmium induces irreversible damage when treated alone and results in reduced fertility potential. $\mathrm{Zn}$ protects the testicular tissue from damages caused by cadmium effectively by acting as chelating agent. Hydroalcoholic extract of Apium graveolens administered with cadmium offers protection against cadmium toxicity very effectively. Zinc chloride and hydroalcoholic extract of Apium graveolens improves morphology, preserves cellular architecture and protects germ cells from apoptosis, protects spermatogenic cells against free radicals, prevents lipid peroxidation, increases serum levels of testosterone and luteinizing hormones by virtue of its antioxidant properties. The most effective protection to the rat testis from cadmium induced damage was offered by hydroalcoholic extract of Apium graveolens $200 \mathrm{mg}$ / Kg body weight), in combination with zinc chloride since it is found to preserve the fertility potential to the greatest extent. How Apium graveolens as an antioxidant and zinc as a chelator work together to prevent the tissue damage by cadmium needs to be explored.

Financial or Other Competing Interests: None.

\section{REFERENCES}

[1] Parízek J. The destructive effect of cadmium ion on testicular tissue and its prevention by zinc. J Endocr 1957;15(1):56-63.

[2] Manca D, Ricard AC, Tra HV, et al. Relation between lipid peroxidation and inflammation in the pulmonary toxicity of cadmium. Arch Toxicol 1994;68(6):364-9.

[3] Shaikh ZA, Vu TT, Zaman K. Oxidative stress as a mechanism of chronic cadmium-induced hepatotoxicity and renal toxicity and protection by antioxidants. Toxicol Appl Pharmacol 1999;154(3):256-63.

[4] Cuypers A, Plusquin M, Remans T, et al. Cadmium stress: an oxidative challenge. Biometals 2010;23(5):927-40.

[5] Thevenod F. Cadmium and cellular signaling cascades: to be or not to be? Toxicol Appl Pharmacol 2009;238(3):221-39.

[6] Rostan EF, DeBuys HV, Madey DL, et al. Evidence supporting zinc as an important antioxidant for skin. Int J Dermatol 2002;41(9):606-11.

[7] Aitken RJ, Fisher HM, Fulton N, et al. Reactive oxygen species generation by human spermatozoa is induced by exogenous NADPH and inhibited by the flavorprotein inhibitors diphenylene iodonium and quinacrine. Mol Reprod Dev 1997;47(4):468-82.

[8] Krishnaiah D, Sarbatly R, Nithyanandam R. A review of antioxidant potential of medicinal plant species. Food and Bioproducts Processing 2011;89(3):217-33.

[9] Khare CP. Indian medicinal plants: an illustrated dictionary. New York, USA: Springer Science 2007. 
[10] Kooti W, Ghasemiboroon M, Asadi-Samani M, et al. The effect of halcoholic extract of celery leaves on the delivery rate (fertilization and stillbirths), the number, weight and sex ratio of rat off spring. Adv Environ Biol 2014;8(10):824-30.

[11] Casalino E, Calzaretti G, Sblano C, et al. Molecular inhibitory mechanisms of antioxidant enzymes in rat liver and kidney by cadmium. Toxicology 2002;179(1-2):3750.

[12] Waisberg M, Joseph P, Hale B, et al. Molecular and cellular mechanisms of cadmium carcinogenesis. Toxicology 2003;192(2-3):95-117.

[13] Xu LC, Sun H, Wang SY, et al. The roles of metallothionein on cadmium-induced testes damages in Sprague-Dawley rats. Environ Toxicol Pharmacol 2005;20(1):83-7.

[14] Biswas NM, Sen Gupta R, Chatopadhyay GR, et al. Effect of atenolol on cadmium-induced testicular toxicity in male rats. Reprod Toxicol 2001;15(6):699-704.

[15] Lafuente A, Gonzalez-Carracedo A, Romero A, et al. Cadmium exposure differentially modifies the circadian patterns of norepinephrine at the median eminence and plasma LH, FSH and testosterone levels. Toxicol Lett 2004;146(2):175-82.

[16] Georgiou M, Perkins LM, Payne AH. Steroid synthesisdependent, oxygen-mediated damage of mitochondrial and microsomal cytochrome p-450 enzymes in rat leydig cell cultures. Endocrinology 1987;121(4):1390-99.

[17] Richburg JH, Boekelheide K. Mono-(2-ethylhexyl) phthalate rapidly alters both sertoli cell vimentin filaments and germ cell apoptosis in young rat testes. Toxicol Appl Pharmacol 1996;137(1):42-50.

[18] Yang HS, Han DK, Kim JR, et al. Effects of alpha-tocopherol on cadmium-induced toxicity in rat testis and spermatogenesis. J Korean Med Sci 2006;21(3):445-51.

[19] Kocak M, Akcil E. The effects of chronic cadmium toxicity on the hemostatic system. Pathophysiol Haemos Thromb 2006;35(6):411-6.

[20] Yang JM, Arnush M, Chen QY, et al. Cadmium-induced damage to primary cultures of rat Leydig cells. Reprod Toxicol 2003;17(5):553-60.

[21] Geva E, Lessing JB, Lerner-Geva L, et al. Free radicals, antioxidants and human spermatozoa: clinical implications. Hum Reprod 1998;13(6):1422-4.
[22] Zini A, de Lamirande E, Gagnon C. Reactive oxygen species in semen of infertile patients: levels of superoxide dismutase-and catalase-like activities in seminal plasma and spermatozoa. Int J Androl 1993;16(3):183-8.

[23] Fridovich I. Superoxide dismutase: regularities and irregularities. Harvey Lect 1983-1984;79:51-75.

[24] Baker HW, Brindle J, Irvine DS, et al. Protective effect of antioxidants on the impairment of sperm motility by activated polymorphonuclear leukocytes. Fertil Steril 1996;65(2):411-9.

[25] Bagheri-Sereshki N, Hales BF, Robaire B. The effects of chemotherapeutic agents, bleomycin, etoposide and cisplatin, on chromatin remodeling in male rat germ cell. Biol Reprod 2016;94(4):81.

[26] Ho E. Zinc deficiency, DNA damage and cancer risk. J Nutr Biochem 2004;15(10):572-78.

[27] Gunn SA, Gould TC, Anderson WA. Zinc protection against cadmium injury to rat testis. Arch Pathol 1961;71:274-81.

[28] Gupta RS, Gupta ES, Dhakal BK, et al. Vitamin C and vitamin $\mathrm{E}$ protect the rat testes from cadmium-induced reactive oxygen species. Mol Cells 2004;17(1):132-9.

[29] Madkour NK. The beneficial role of celery oil in lowering of di(2- ethylhexyl) phthalate-induced testicular damage. Toxicol Ind Health 2014;30(9):861-72.

[30] McLachlan RI, O'Donnell L, Meachem SJ, et al. Identification of specific sites of hormonal regulation in spermatogenesis in rats, monkeys, and man. Recent Prog Horm Res 2002;57:149-79.

[31] Kerishchi P, Nasri S, Amin G, et al, eds. The effects of Apium graveolens extract on sperm parameters and $\mathrm{H}-\mathrm{G}$ hormonal axis in mice. Hamedan, Iran: Proceedings of the $20^{\text {th }}$ Iranian Congress of Physiology and Pharmacology Sep, 2011.

[32] Shittu LAJ, Bankole MA, Oguntola JA, et al. Sesame leaves intake improve and increase epididymal spermatocytes reserve in adult male Sprague Dawley rat. Sci Res Essays 2007;2(8):319-24.

[33] Wang C, Zhang Y, Liang J, et al. Impacts of ascorbic acid and thiamine supplementation at different concentrations on lead toxicity in testis. Clin Chim Acta 2006;370(1-2):82-8. 